\title{
RELAÇÕES DIALÓGICAS EM ENUNCIADOS VERBOVISUAIS DA REVISTA NOVA ESCOLA: ESTUDOS DISCURSIVOS E ENSINO-APRENDIZAGEM EM MATEMÁTICA
}

\section{DIALOGICAL RELATIONS IN VERBOVISUAL STATEMENTS IN NOVA ESCOLA MAGAZINE: DISCURSIVE STUDIES AND TEACHING-LEARNING IN MATHEMATICS}

\author{
Carlos Eduardo da Silva Ferreira ${ }^{98}$
}

\begin{abstract}
RESUMO: Este artigo retoma debates realizados em minha dissertação de mestrado (FERREIRA, 2015). A partir da perspectiva teórica da Análise Dialógica do Discurso, investigo como são construídas as compreensões sobre o movimento de circulação e emergência de vozes que ressignificam o sentido de aula de Matemática na revista Nova Escola. Em maior especificidade, para este trabalho, fazendo uma leitura das capas de revistas da Nova Escola do período de março/1986 a dezembro/2012, pretendo explicitar relações dialógicas permeadas nestas materialidades discursivas verbovisuais, a fim de colocar em cena vozes que constroem discursos sobre a aula de matemática.
\end{abstract}

PALAVRAS-CHAVE: Relações dialógicas. Círculo de Bakhtin.Nova Escola. Matemática.

\begin{abstract}
Thisarticleis a reumedof debates held in my master's dissertation (FERREIRA, 2015). From the theoretical perspective of Dialogical Discourse Analysis, I investigate how understandings are built on the circulation and emergence of voices that reaffirm the meaning of the Mathematics class in Nova Escola magazine. More specifically, for this work, reading the covers of magazines from the Nova Escola from the period of March 1986 to December 2012, I intend to explain the dialogic relations permeated by these verbal visual discursive material, in order to put on the scene voices that construct discourses about the math class.
\end{abstract}

KEYWORDS: Dialogicalrelationships. Bakhtin Circle.Nova Escola.Math.

\section{$1 \mathrm{Um}$ percurso desta pesquisa}

\begin{abstract}
Há sempre uma espessura e uma instabilidade que se devem levar em conta e que remetem à própria espessura e instabilidade do objeto e do saber que estão se tecendo no texto. Objeto que não pára nunca de se mexer, a cada vez que dele se fala, assim como um caleidoscópio (AMORIM, 2012, p. 11).
\end{abstract}

Por meio da análise dos discursos referentes ao ensino de matemática em capas produzidas pela revista Nova Escola,pudemos construir na dissertação uma rede de dados de como são pensadas/refletidas/preparadas relações diretas e radiais (difusas) sobre o discurso entre professor-aluno-conhecimento durante o processo do momento aula. Fizemos metodologicamente uma análise das capas de Nova Escola demarcando e correlacionando períodos e características entre 1986 e 2012.

O corpus foi composto, além das capas de revista, por exemplos de gêneros de reportagem/matérias na correlação com planos de aula. Isto foi decisivo para realizarmos uma análise discursiva que sobre-elevou mudanças de guinada/de foco/de perspectivas que a revista Nova Escola empregou ao longo dos anos no empreendimento de construir imagens sobre elementos e atores da esfera pedagógica. Esta escolha metodológica permitiu também

\footnotetext{
${ }^{98}$ Mestre em Linguística e Língua Portuguesa pela Faculdade de Ciências e Letras da UNESP de Araraquara e doutorando no mesmo programa. Doutorando também no Programa de Pós-Graduação Multiunidades em Ensino de Ciências e Matemática (PECIM), na UNICAMP. Graduando em Licenciatura em Ciências Naturais e Matemática pela UNIVESP. karloseduardoo@yahoo.com.br
} 
que confrontássemos relações entre a voz da instituição da revista (capa e reportagens) e vozes dos professores ("depoimentos" e planos de aula) - ainda que perpassadas pela escolha da revista.

Atualmente a revista Nova Escola é uma publicação de periodicidade mensal voltada à comunidade de professores do ensino Básico. Lançada em 1986 pela Fundação Victor Civita, a revista aborda diversos assuntos da área educacional, sob as mais variadas formas expressivas de textos jornalísticos: entrevistas com especialistas, artigos, relatos de experiências, ideias para sala de aula e seções destinadas a divulgação de trabalhos desenvolvidos em diferentes comunidades do país.

Enquanto meio de comunicação de atividades culturais, a revista se consolida por meio de seu conteúdo, propondo uma desmistificação de ideias/abordagens ligadas ao contexto de ensino/aprendizagem escolar. Tendo em vista a importância desta revista no tocante à divulgação de ações educativas e consequentemente como meio de atrair o leitor para o consumo, este estudo buscou apresentar uma análise do trabalho com vozes, via Análise Dialógica do Discurso, sobre discursos veiculados por esta/nesta revista educacional no decorrer do período de junho de 1986 ( $1^{\text {a }}$ edição) a dezembro 2012 (data de início de nossa pesquisa). Investigamos, neste trabalho, exemplos de como são construídas compreensões sobre o movimento de circulação e emergência de vozes que ressignificam os conceitos sobre aula de Matemática na revista Nova Escola refletindo sobre como discursos atribuídos ao professor de matemática se manifestam a respeito do acontecimento aula no decorrer do período de pesquisa.

A fim de sintetizarmos os resultados da pesquisa para que eu oferte exemplos do trabalho dialógico em discursos verbovisuais sobre que estavam, coloco, a seguir, como conclusões, cinco pontuações sobre estas investigações:

1- Podemos dizer que a revista instaura uma discussão mobilizando a memória do fracasso escolar, atravessando desde discursos excludentes do saber-fazer em matemática até discursos da democratização do ensino (otimistas) via alguma pedagogia específica (sociointeracionismo, construtivismo, Teoria das Inteligências Múltiplas etc), a fim de instaurar uma contribuição "salvadora" vinda dela.

2) Em nossos caminhos abdutivos, tomando como corpus para análise o gênero capa, temos observado que, em suas alterações no decorrer dos anos, Nova Escola altera seu projeto gráfico e editorial. Tendo em vista a importância desta revista em relação à divulgação de ações educativas e, consequentemente, como meio de atrair seus leitores para o consumo (no passar dos anos, Nova Escola vem se constituindo como um importante veículo de divulgação de ideias e práticas pedagógicas junto aos professores), há certas implicações das concepções sobre ensino/aprendizagem de matemática disseminadas por meio de suas páginas. Investigamos uma relação entre as reestruturações gráfico-editoriais e os discursos sobre o acontecimento da aula de matemática. Entendemos que a revista anteriormente se posiciona de modo bastante crítico, interdisciplinar em suas falas e éportadora de embates ideológicos explícitos a partir da fala de seus pesquisados/entrevistados. Atualmente, ela tem se mostrado uma revista com mais de $1 / 3$ de suas páginas sendo propagandas, tem havido uma intensa fragmentação disciplinar, além de não trazer na voz de professores do Ensino Básico polêmicas explícitas sobre o atuar pedagógico. A revista traça uma demonização das práticas de um modo geral, mas na voz do professor pormenorizam-se conflitos.

3) O discurso salvacionista é fundante na colocação da voz da revista e nos rearranjos das vozes dos professores de Matemática nos gêneros capa e reportagem/plano de aula ao longo das edições. É por meio de um cenário de crise que Nova Escola se configura, dando respostas de resolução aos professores, classe que teria dificuldades em assumir posicionamentos frente à realidade socioeconômica discrepante no Brasil. Há uma denúncia, assim, de uma má formação profissional. 
4) No que compete ao ensino de Matemática, o fazer matemático é trabalhado com operações elementares. Mesmo que ditas como "básicas", Nova Escola expõe que a compreensão social delas está distante, haja vista, o modo de operacionalização de tal.

5) Tanto as capas de Nova Escola quanto as reportagens do período analisado representam uma desarticulação entre teoria e prática nas atividades do fazer matemático na Escola Básica.

Sobre esta nossa pesquisa, se há a incômoda sensação da "mistura" de uma abordagem linguístico-discursiva ligada às humanidades e a uma temática com configuração pouco comum a esta base, no campo das Exatas, gostaríamos de ressaltar que o estranhamento e o número baixo de atrelamentos interdisciplinares estão ligados a um histórico formal das práticas dos sujeitos em nossas vivências sociais. É justamente nesta linha que este estudo também se configura: é "um trabalho de pesquisa e uma ação política, não de políticas partidárias, mas de denúncia junto à classe docente", como diria Armando Maia, o camelô da Matemática do Largo da Carioca, matéria veiculada na revista Nova Escola ( ${ }^{\circ}{ }^{\circ} 49$, junho/1991, p. 54).

\section{Relações entre domínio teórico e práticas analíticas}

Os estudos discursivos do Círculo de Bakhtin, teoria na qual nos pontuamos como referente fundamental para instabilizarmos nossas análises, orienta-nos na direção da interpretação discursiva, numa construção de sentidos articulada na história e nas dinâmicas sociais que a produzem, possuindo nestes dois pontos - linguístico e histórico - um posicionamento analítico perante a construção do ser humano, a saber: construção de si em si e com o outro.

Como proposta de análise bakhtiniana, estamos entendendo que os variados conceitos desenvolvidos pelo círculo bakhtiniano estão interligados em si numa perspectiva ampla, num mosaico emaranhado e coeso. Se quisermos analisar o corpus em estratos, poderemos, mas sem perder de vista que o diálogo é o elemento fundante das reflexões nesta área (BRAIT, 1994). Este nosso trabalho analítico toma um cenário de debates críticos toda enunciação: dependendo de como abordamos essa dinâmica analítica (estilo, forma, entre outros), nosso discurso vai se posicionando acerca de determinadas ideologias e corroborando, assim, a importante pontuação do círculo bakhtiniano de que o signo é ideológico (BAKHTIN/ VOLOCHINOV, 1992).

Beth Brait (1994,p.11) nos coloca que um projeto comum do Círculo é o reconhecimento da natureza dialógica da linguagem: "a natureza dialógica da linguagem é um conceito que desempenha papel fundamental no conjunto das obras de Mikhail Bakhtin, funcionando como célula geradora dos diversos aspectos que singularizam e mantêm vivo o pensamento desse produtivo teórico".

As relações dialógicas dos discursos, tramas de ser/significar(-se) no mundo, e os confrontos da alteridade dessas relações tomam destaque no contexto desta pesquisa encaminhando-a, portanto, a perspectivas que buscam o encontro com o outro, compartilhando experiências, reflexões e valores que se alteram mutuamente. Sendo assim, nesta abordagem teórica, o outro deixa de ser uma realidade abstrata a ser definida e traduzida por um conceito. Em outras palavras, metodologicamente, o sujeito da pesquisa é visto como alguém cuja palavra se confronta com a do pesquisador, refratando ideologias e exigindo-lhe resposta, configurando uma cadeia enunciativa de enunciações de valores. Em contrapartida, a palavra do pesquisador recusa-se a assumir a aura de neutralidade imposta pelo método e integra-se à vida, participando das relações e das experiências, muitas vezes contraditórias, que o encontro com o outro proporciona. 
Atribuir sentidos é ler a palavra como signo que reflete e refrata valores ideológicos advindos de uma memória discursiva dos sujeitos. Nossa posição como pesquisadores analistas do discurso coloca-nos a interpretar projetos de dizer dos sujeitos numa determinada esfera enunciativa ou em lugares institucionais. Estão colocadas aqui relações de alteridade que indicam construções de imagens que os sujeitos operam em suas enunciações: um eu pra mim (de si), um outro pra mim (do outro), e um eu pro outro (uma atividade exotópica em si, sobre si, projetando o que o outro vê do $e u$ ).

Estamos entendendo, segundo os estudos do círculo bakhtiniano, que a noção de ideologia marca a impossibilidade de se conceber uma neutralidade nos sistemas de expressão (linguagem), fazendo com que entendamos que os enunciados contêm marcas de olhares sobre o mundo, além de guardarem sinais de mudanças sociointeracionais; colocamos destaque no entendimento de uma máxima: a palavra faz-se signo ideológico visto que acumula as entonações do diálogo vivo de que é matéria, ou, nos termos do Círculo, "cada palavra se apresenta como a arena em miniatura onde se entrecruzam e lutam os valores sociais de orientação contraditória" (BAKHTIN/VOLOCHINOV, 2004, p. 66).

Os discursos materializam as ideologias, as formas de ver o mundo. Sendo assim, não há como separar radicalmente este plano, digamos, ligado fortemente a umideário de pontos de vista maliciado pela vivência (ideologia) da forma materializante/materializada (discurso). Ideia versus matéria, abstrato versus concreto não se dicotomizam nesta nossa perspectiva, mas sim realizam jogos de representação pelos sujeitos. Aquilo a que temos acesso, então, são osvalores ideológicos, tramas discursivas que nos farão interpretar acontecimentos na relação de uma dinâmica de valores, podendo o pesquisador, por exemplo, confrontar-se com sua visão de mundo e seu projeto de dizer perante os olhares múltiplos de seu corpus em análise.

Toda essa trama de dizeres que constituem os sujeitos liga-se ao que Bakhtin denomina diálogo. Tomemos que com Bakhtin o diálogo é o cerne da constituição do sujeito, inclusive do conhecimento no campo das Ciências Humanas. Sendo assim, não há um único ser humano cuja condição de humanidade não advenha da sua interlocução com os demais, posto que sua existência é dotada de significados anteriormente predicados e marcada pelo modo como um se posicionará na continuidade a essa interlocução.

Voz é um conceito central nesta pesquisa. Ele é compreendido como uma cadeia enunciativa ligada a um sujeito que se expressa e está intimamente ligada à interpretação de sujeitos ao "ouvir"/compreender um posicionamento social. Podemos refletir sobre vozes, noção plural, já que estamos trabalhando com o embate da constante instabilidade do devir e, por isso, descobrimos uma voz por meio da aproximação de outras (via cotejamento de enunciados). Colocar que a voz é histórica, temporal, cultural não a delimita muito.

Tentemos pontuá-la com maior clareza: a voz é uma cadeia enunciativa de tonalidade valorativa que assumirá, por interpretação dos sujeitos, uma destinação ideológica, marcando certas especificidades nos sujeitos do discurso. Esta destinação específico-interpretativa faznos demarcar lugares sociais, estes sendo produtos/resultados da significação das instâncias discursivas (sujeitos, espaço, tempo, ideologias).

A voz permite o reconhecimento do estilo de um grupo de sujeitos, uma marca de uma determinada classe social. A voz emitida permite uma orientação ideológica de referências a um lugar social, uma orientação de uma memória dos dizeres situada em grupos específicos de sujeitos.

O nome voz coloca em diálogo algumas outras categorias bakhtinianas referentes à sonoridade. Apesar de conceitos teórico-metodológicos (filosóficos por base), estes guardam uma relação à escuta: ouvir vozes e interpretá-las; ecos de vozes de enunciados outros; ressonância de vozes; reverberação das vozes.

Desta forma, corroboramos a noção de que a voz apenas aparecerá na relação com outros posicionamentos. No enunciado "sempre estão presentes ecos e lembranças de outros 
enunciados, com que ele conta, que ele refuta, confirma, completa, pressupõe e assim por diante" (FIORIN, 2008 p. 21).

À pergunta de quem é essa voz podemos responder, por exemplo, é a voz do professor, é a voz da revista, é a voz dos excluidos da sociedade, é a voz dos marginais, são as vozes dos moradores de ruas. Podemos pontuar que estas são respostas aliadas a cenários historicamente situados, delineados por um viés de referenciação.

No processo de busca da estabilização provisória dos sentidos, a voz se posiciona como fonte de um sentido personalizado, tendo na base um sujeito autor-pessoa. É válido ressaltar que, como nos coloca Bubnova (2011), a produção de sentidos pelos sujeitos:

não se trata de uma "metafísica da presença", dos sentidos pré-existentes e imóveis, nem de algo fantasmagórico, mas de um constante devir do sentido permanentemente gerado pelo ato-resposta, que vai sendo modificado no tempo ao ser retomado por outros participantes no diálogo (p. 274).

Podemos dizer que o conceito voz se identifica com opinião, ideia, ponto de vista, postura ideológica. Desta forma, como nos mostram os estudos bakhtinianos, na obra de Dostoiévski, o herói de uma novela "não é uma imagem, e sim a palavra plena, a voz pura; não o vemos, mas o escutamos" (BAKHTIN [BAJTÍN], 1994 [1929], p. 45 apud BUBNOVA, 2011, p. 276). "A compreensão do mundo (de realidades) é modelada por meio de "visões do mundo materializadas nas vozes"” (BAKHTIN [BAJTÍN], 1996, p. 354 apud BUBNOVA, 2011, p. 276).

A partir desta discussão inicial que tomamos, gostaríamos de desenvolver uma linha de reflexão a respeito deste conceito do círculo bakhtiniano, pautando-nos na relação dialógica que estabelecemos a seguir: voz de e voz sobre.

Para ampliarmos esta proposta conceitual, é interessante recorrermos a mais um conceito desenvolvido pelo círculo bakhtiniano: polifonia. A noção metafórica de polifonia em sua relação com o diálogo refere-se à orquestração de vozes em diálogo aberto, sem solução. Na busca dos sentidos, a polifonia instaura um debate caótico do devir, a fim de realizar o trabalho epilinguístico (atividade de linguagem) de referenciações e estabilizações. Atrelada à interpretação de valores sociais em circulação num determinado tempo e espaço possíveis, a polifonia é uma característica das cadeias expressivas, das materialidades resultantes de uma determinada prática discursiva (gênero), numa mistura de sons, de vozes, de sujeitos, de jogos de percepções, de escutas num emaranhado conjunto em que nós sujeitos vamos estabelecendo referenciais e valorações.

O que estamos chamando de voz de liga-se à referenciação de um lugar social na interpretação polifônica: a voz do professor, a voz do aluno, a voz do analista, a voz do louco. Configura-se, aqui, uma remissão não a um sujeito em especificidade, mas sim a um grupo social, sendo sua voz materializada no signo por meio do já-dito, por uma memória discursiva que estabiliza determinadas nuances recorrentes. Podemos dizer que, neste sentido, nesta conceituação que instauramos há uma aproximação e um distanciamento relacionado ao conceito de autoria, pois este implica delimitar a explicitação do sujeito e aquele não, no entanto há uma implicação.

Já a reflexão referente à noção de voz sobre coloca-nos não frente a um grupo determinado, como pontuamos anteriormente, mas sim a uma remissão ideológica, temática, instaurando uma referenciação relacionada ao assunto. Desta forma, podemos ter investigações relacionadas àsvozes sobre o ensino de matemática, sobre a aprendizagem escolar, sobre o que é analisar, sobre a loucura.

Voz de e sobre não se opõem uma a outra, pelo contrário. Ambasformas se constroem nas relações de referenciação e valoração. Temos uma distinção entre elas no tocante à fonte: 
a primeira referenciando e oferecendo valorações com ênfase nos sujeitos e a segunda referenciando e oferecendo valorações com ênfase nas relações ideológico-temáticas.

As sequências de sentido, instigadas pelas vozes, constituem um diálogo permanente, inacabado, instaurando um efeito polifônico para estabilizações de sentidos. As palavras tornam-se enunciado e adquirem um autor, isto é, um criador de um enunciado determinado cuja posição está sendo expressa. Aqui, é a voz sobre - um referencial temático - que toma partido. A voz é também a metáfora do corpo, da presença necessária dos sujeitos no diálogo, no tempo aberto. Instaura-se, aqui, a voz de, marcando um lugar social.

\title{
4 Capas da revista Nova Escola: o ensinar-aprender em jogos de imagens
}

Em sua tese de doutorado, Mário Cândido de Athayde Júnior (2006) traz que no entremeio destas duas polarizações de modelos conceituais que,

\begin{abstract}
ao longo das sucessivas reformas que se processaram na história recente da educação brasileira, a relação entre a educação escolar e a sociedade foi determinando o papel que a educação escolar deveria cumprir, de acordo com os interesses econômico-políticos dominantes em diferentes momentos históricos. Da mesma forma, os projetos de formação de professores em serviço foram sofrendo alterações que refletiam diferentes concepções de educação e seus respectivos projetos políticos. Neste sentido, a trajetória da formação em serviço de professores não pode ser descolada da história da sociedade e da educação brasileira (p. 156).
\end{abstract}

Ao relacionarmos expectativas educacionais de uma sociedade num determinado tempo, principalmente ao olharmos documentos oficiais legitimadores de atuações, o papel social incumbido aos sistemas escolares configura-se, é forjado por uma política de treinamentos visados a certas correspondências ao mundo social. Sendo um texto/discurso, a documentação oficial não é neutra. Os textos legais marcam interesses de grupos detentores de poderes político-econômicos. Assim, a atuação dos "atores educacionais" (professores, gestores etc) se firma no cumprimento das exigências legais. A tradução disto à prática das ações juntamente aos alunos/estudantes liga-se a mais um setor executivo dos comandos legislativos. O processo educacional é visto, neste sentido, fundado nos regimentos políticos. Como discursos que são, também, nestas práticas do dia a dia coabitam o constante jogo conflituoso das lutas ideológicas que articulam em debates e circulações discursivas.

Como viemos relatando, nossa proposta aqui é analisar um recorte de discursos veiculados na revista Nova Escola. Esta revista, voltada aos professores - inicialmente como subtítulo de "Para professores do $1^{\circ}$ grau", e nos dias atuais "A revista de quem educa" -, aborda múltiplos assuntos da área educacional, em virtuosa diversidade de gêneros jornalísticos: entrevistas com especialistas, artigos, relatos de experiências, estratégias/suportes para sala de aula, seções destinadas à divulgação de trabalhos desenvolvidos pelo país, entre outros.

No intuito de disseminar atividades culturais, a revista se firma no mercado editorial brasileiro. Tendo em vista a influência que esta revista possui no meio de circulação pelo Brasil - nãohá outro impresso de temática educacional entre as 30 revistas de maior circulação nacional ${ }^{99}$ - e suas divulgações de abordagens educativas, este estudo busca analisar as diferentes - ou não - concepções do construto aula nos discursos veiculados pela revista e dirigidos à área da Matemática, em específico no campo da Educação Matemática.

99 Dados estes verificáveis no Instituto Verificador de Circulação (IVC), além de constarem na página da Associação Nacional dos Editores de Revistas (ANER): <http://www.aner.org.br/>. 
Para analisar as capas neste viés discursivo da análise dialógica temos como foco debates sobre aspectos do gênero capa, trazendo valores, ideologias e vozes presentes em enunciados. A capa, como gênero discursivo, materializa uma chamada para uma leitura de outros textos; assim ela antecipa de modo chamativo assuntos internos, apresentando um diálogo entre enunciador (revista) e interlocutores.

Como produto de venda, as capas das revistas se colocam como um mostruário, um chamariz que, no caso de revistas vendidas em bancas de jornal vai, muitas vezes, determinar o volume de vendas. De um outro ponto de vista - dos leitores das revistas/dos periódicos - as capas promovem uma chamada que se circunscreve a alguma temática a ser debatida. Neste sentido, conhecer o projeto de dizer de cada instituição da mídia é um processo significativo para a atribuição de sentidos. É importante ressaltar aqui - e poderemos analisar isto em Nova Escola - que, se entendidas como um gênero de discurso, as capas vão se transformando no decorrer dos processos sócio-históricos; gostaríamos de ressaltar em nossa análise alguns efeitos de sentidos que esses rearranjos do gênero capa podem configurar no panorama educacional, já que estamos buscando vozes sobre o acontecimento aula de matemática.

Para desenvolvermos nossas reflexões acerca dos discursos sobre aula de matemática em Nova Escola, o gênero capa pode nos apresentar uma representação exemplar de valores discursivos que almejamos debater, pois a expressividade deste gênero funde tanto a semiose verbal como a não verbal, além de a capa ser uma estampa, um abre-alas de uma edição.

Passemos a algumas análises. Foram 258 capas coletadas de março de 1986 a dezembro de 2012. Para que você leitor possa ir acompanhando nossos debates, a seguir estão indicações sobre o link que você pode acessar: da p. 126 à p. 144 em https://drive.google.com/file/d/0B5ZiXvsuhQmNQUFuLXpoQWJHeXc/view?usp=sharing; e https://drive.google.com/file/d/0B5ZiXvsuhQmNUVJQeWh4T110LWs/view?usp=sharing.

As capas, enquanto gêneros discursivos, se constituem por semioses na conjuntura sincrética, reportando a discursos ditos não verbais - fotografias, desenhos, ilustrações - e signos linguísticos, os verbais - cabeçalho, chamadas. O encabeçamento ou cabeçalho - a apresentação visual permanente que possibilita uma rápida identificação da revista por seus leitores - contém o nome, a data, o número da publicação, o preço e outras informações essenciais que variaram no decorrer do tempo. As chamadas ou manchetes dizem respeito aos pequenos títulos das matérias com destaque entre as contidas em uma edição e possuem como foco a atração do leitor para que ele se remeta às matérias completas, no interior da publicação. A chamada principal representa a reportagem considerada a mais relevante pelo conselho editorial da revista e tem um título com letras em tamanho maior que as demais. Evidentemente, a imagem que irá compor a capa destacará esta chamada. As chamadas, juntamente com as imagens, são um dos fatores mais visíveis para atrair a atenção do leitor, porém há posições antagônicas no que se refere à questão da primazia do enunciado escrito sobre o enunciado imagético ou vice-versa. Em nosso entendimento, consideramos que esse "fisgar" do leitor dá-se na relação com o sincretismo entre língua escrita e imagem não verbal.

Como ressalta Silveira (2006) em seus estudos sobre capas da revista Nova Escola, as capas da revista, desde sua primeira edição, em março de 1986 , até a edição de $n^{\circ} 79$, de outubro de 1994, seguem um mesmo padrão estético apresentando pequenas variações. Podemos demarcar, também, que o nome da revista explicitado no material publicado possui, nessas suas primeiras edições de 1986, a palavra NOVA, escrita na cor amarela em Caixa Alta, em sentido vertical; esta palavra aparece sobreposta ao $E$ da palavra Escola, que está disposta na horizontal, em Caixa Alta e Baixa, na cor verde. A partir do $\mathrm{n}^{\circ} 3$ (maio/1986), a palavra Nova passa a ocupar uma posição distinta da anterior, alterando suas cores: passa a ser escrita na horizontal, em Caixa Alta e Baixa, na cor laranja, logo acima da letra $c$ da palavra Escola. Assim permaneceria até $o \mathrm{n}^{\mathrm{o}} 6$ (setembro/1986), quando então aparece sobre a letra $o$ da palavra Escola, em Caixa Alta. A partir do exemplar de no 68 (agosto/1993), a palavra NOVA 
alterna suas cores entre laranja, preto, branco e amarelo. Todavia, a palavra Escola se manteve durante todos esses anos na cor verde, sempre escrita em Caixa Alta e Baixa.

Podemos interpretar que, ao serem enunciadas, estas cores estabelecem valores correspondentes a um simbolismo pátrio brasileiro, haja vista que, no ano anterior ao lançamento do periódico - o Brasil acabara de sair de um período repressivo instaurado pela ditadura militar -, houve o início da redemocratização com a eleição de Tancredo Neves que, embora indireta, traz um entusiasmo à maioria da população brasileira, suscitando um sentimento nacionalista reavivado no qual a educação teria um importante e significativo fundamento na formação dos cidadãos. Chamemos a atenção para o título da revista em que há uma ênfase à palavra Escola, não somente por seu tamanho em comparação à palavra Nova - aproximadamente $3 \mathrm{~cm}$ a mais de altura e $12 \mathrm{~cm}$ a mais de largura - mas sim pela cor. A escola seria o lugar privilegiado para a constituição crítico-moral na vivência dos sujeitos. Este esforço espelha na capa de Nova Escola,neste primeiro momento (1986-1995), montando um quadro compreensivo-discursivo que nos permite firmar que esta instituição Nova Escola está compreendendo que o professor é o agente motor desta "nova sociedade" pós-ditatorial, e que este deve centralizar a revista como um material-base para esta 'missão' de vida.

Nova Escola: quais significações podemos encontrar nestes termos? "Nova" de inovação, de novas atitudes na escola. Relacionemos, também, que no Brasil, no início do século XX houve o movimento escolanovista (Escola Nova) - nome espelhado dos termos pautado por um modelo proposicional que buscaria nas práticas situacionais da vivência a base de um modelo escolar, da experiência concreta para um juízo de conceitos.

Analisemos a alteração dos slogans no decorrer das enunciações na capa. Logo abaixo do título da revista, encontra-se seu subtítulo: Para professores do $1^{\circ} \mathrm{Grau}$, seguido pelos respectivos ano e número de edição, mês e ano de publicação, e preço do exemplar. Podemos dizer que o termo linguístico "para" destina não somente uma demarcação de um interlocutor (para alguém), assim como, se colocarmos em relação título e subtítulo temos o seguinte enunciado: "Nova Escola para professores do $1^{\circ}$ grau", ou seja, desta maneira otermo "para" enuncia um direcionamento com finalidades de alteração do quadro funcional vigente direcionado os professores desta categoria a uma perspectiva outra.

Uma característica que destacamos neste período (1986-1994) é a opção por apenas uma chamada de capa, ao contrário de inúmeras outras publicações que materializam várias chamadas. Temos que quando a revista nos apresenta, além da chamada principal, uma outra informação sobre seu conteúdo, ela se utiliza de tarjetas, sempre postas no canto superior direito, em diagonal, na cor amarela (SILVEIRA, 2006).

Em 1995 houve uma expoente alteração do quadro gráfico da revista. Há uma modernização desta imprensa: o papel do material é alterado; os formatos das letras também o são. O signo Nova, de Nova Escola, é miniaturizado e posto à esquerda e na vertical, posição esta que permanece até hoje.Da edição de fevereiro até dezembro de 1995, o quesito gráfico passa por duas alterações maiores: o tom verde-amarelista dá espaço a uma visualidade pluricolorida.É a revista se aproximando às novas tecnologias que se ajustam às expressividades do contemporâneo. As imagens tendem a tomar toda a página, configurando um pano de fundo para a o título da revista. Silveira (2006, p.39) destaca que tanto as imagens quanto as chamadas de capa apontam indícios que atingem esta maneira de produção "pósditatorial": "intenção do editor, expectativas do público leitor, conteúdo da revista, disponibilidades/possibilidades tecnológicas do momento".

Nessas duas alterações de 1995, de fevereiro a junho temos o slogan como $A$ revista para o professor de primeiro grau e depois ele muda para $A$ revista do ensino de primeiro grau. Já em 1998, temos $A$ revista do ensino fundamental, enunciado este que foi adaptado devido às mudanças da política de ensino brasileiro, uma vez que o termo 'ensino 
fundamental' é tratado no lugar de " $1^{\text {o }}$ grau", modificação estabelecida pela Lei de Diretrizes e Bases da Educação Brasileira, sancionada em 20 de dezembro de 1996.

Como revista do ensino fundamental, podemos interpretar que o grupo destinatário deste subtítulo agrega não somente a categoria dos professores, mas sim todo um grupo escolar, ampliando seus interlocutores, tais como diretores, coordenadores e outros funcionários.

No ano de 2000, o slogan da publicação é alterado novamente. Temos agora A Revista do Professor. Desta forma, podemos colocar que Nova Escola deixa então de ser a revista representativa de um determinado nivelamento de ensino e torna-se "porta-voz" de uma categoria profissional. Analisemos que temos um determinante (A revista...) reforçando uma exotopia de que é esta revista reconhecida por aqueles que ela representa. Esta questão será proveitosa em nossas análises, quando discutirmos efeitos de sentido das relações entre os gêneros do discurso reportagens-planos de aula.

Em 2003 o título passa por nova formatação. É neste ano também que podemos verificar uma acentuada elevação de informatividade trazidas à capa. Mas a exploração do cenário da capa só será mais exacerbada, neste sentido de aproveitamento do espaço para inúmeras informações de diversas áreas - além de um projeto gráfico mais dinâmico, que chega a usar caricaturas, ou objetos se sobrepondo parcialmente ao nome da revista - na alteração de 2006, quando a revista se coloca como A revista de quem educa. Analisemos, desta maneira, como se altera o quadro do projeto de dizer de Nova Escola direcionado a seus interlocutores. Há um alargamento deste campo; de um mais específico a um mais amplo. É possível a interpretação de que a preocupação "missionária" da revista é educar o processo educacional da Escola Básica, ou seja, ser um manual educativo aos educadores, atendendo uma maior quantidade de sujeitos por circular de forma expressiva e, como debateremos, estrategicamente, no âmbito escolar. Isto é entender que a escola, assim como proposto e feito pelo periódico, deve atentar para um contexto bem mais complexo que a sala de aula e, assim, dar conta desta complexidade.

Trazemos, a seguir, um grupo do corpus para análise. Antes de as colocarmos, também destacamos tópicos de algumas edições que não traziam o tema explícito sobre Matemática (vide anexos), mas discursivizam paralelamente nas capas sobre aula de matemática; fazemos isto a fim de montarmos um cenário de cercanias em nossas análises. Destacamos os seguintes enunciados retirados destas capas:

Enunciado I:

"Caminhos certeiros para apresentar a álgebra" - Edição 224, agosto de 2009.

Enunciado II:

"A maneira mais eficaz de iniciar o ensino da raiz quadrada" - Edição 230, março de 2010 .

Enunciado III:

“A forma certeira para ensinar ângulos” - Edição 231, abril de 2010

Enunciado IV:

“Na entrevista: por que o ensino de Matemática é tão fraco?" - Edição 199, janeiro-fevereiro de 2007.

Enunciado $V$ :

"O jeito certo de ensinar a função afim" - Rol de sequências didáticas no site de Nova Escola. 


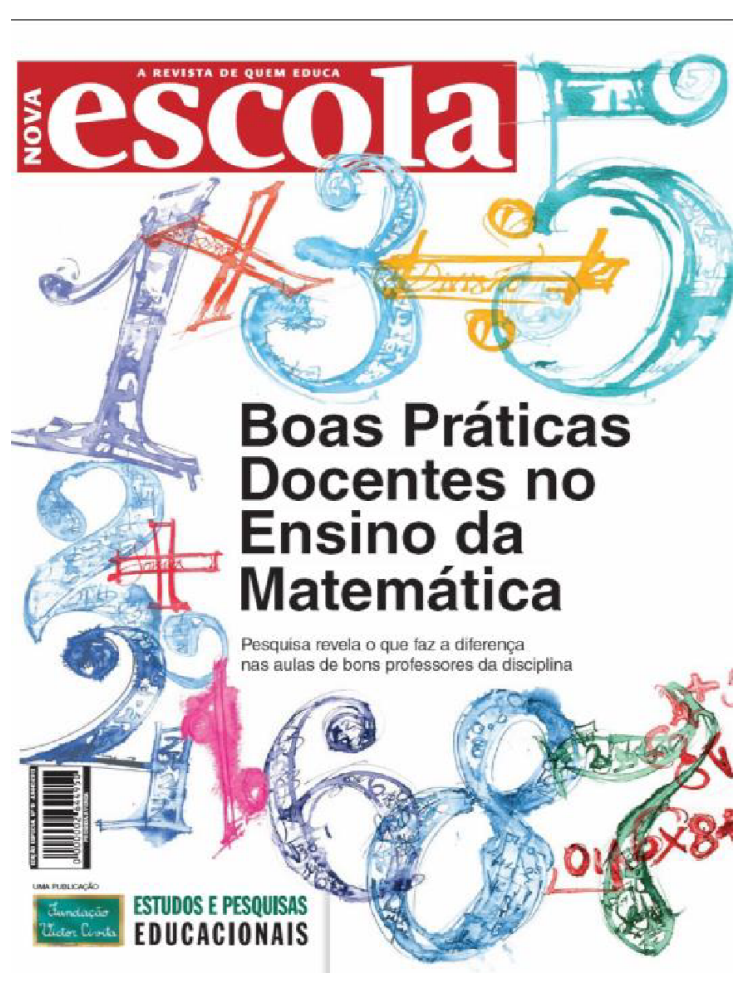

Fig. 1: Edição especial nº 10 de Nova Escola, jun-2012.

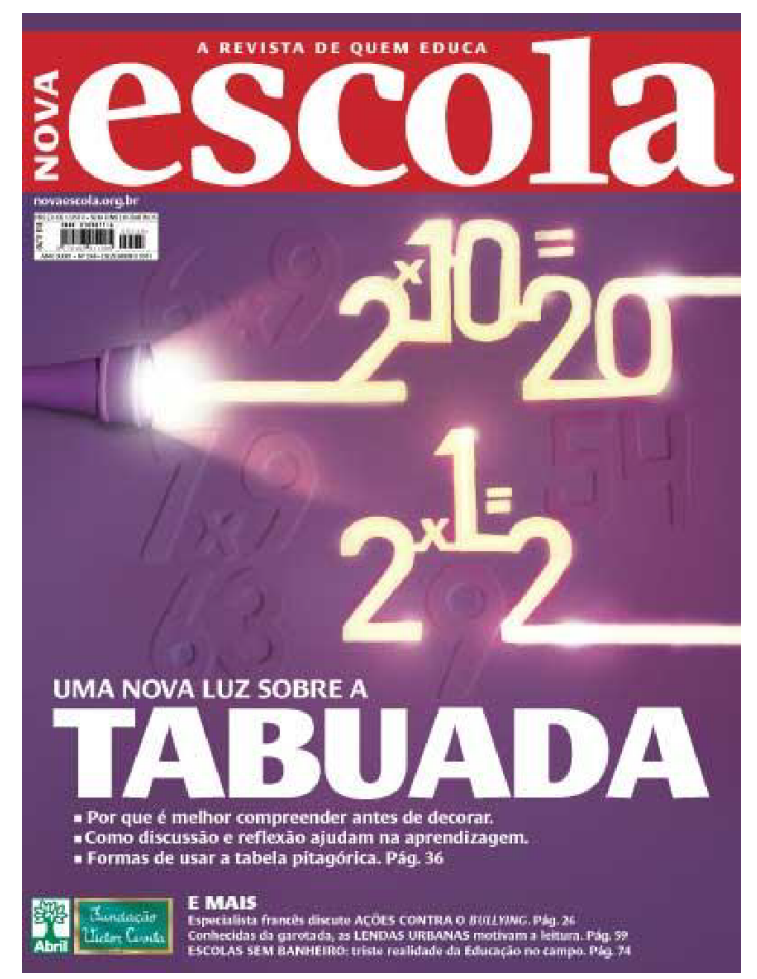

Fig. 2: Nova Escola, ed. 248, dez-2011.

Desses oito enunciados produzidos pela Nova Escola, podemos depreender uma cadeia enunciativa orientando-nos à interpretação de que há valores ideológicos ligados à produção de discursos sobre o fracasso escolar, à incapacidade dos sujeitos dentro do sistema escolar. Isto se dá, por exemplo, pela análise de marcas pragmático-semânticas: 'Caminhos certeiros'(I), 'A forma certeira' (III), 'O jeito certo' (V), 'A maneira mais eficaz' (II).

Se há um "jeito certo", um/a "caminho/forma certeiro/a" e uma "maneira mais eficaz" podemos entender, por inferência, o pressuposto de que há um "jeito errado", um/a "caminho/forma não certeiro/a" e uma "maneira menos eficaz". Esse espaço pressuposto encena o estado situacional de ações ocorridas na escola, ou seja, o discurso sobre o acontecimento da aula de matemática enunciado por Nova Escola tem figurativizado esta aula/este ensino/esta aprendizagem de modo deficitário.

Também ocorre em (a) "por que o ensino de Matemática é tão fraco?" (nº 199, janfev 2007 - em anexo) e (b) "Boas práticas docentes no ensino da Matemática" (Fig. 1).

Sobre (a), a instauração da dúvida (por que) remonta um discurso-resposta (no sentido dialético-dialógico) perante um cenário entendido por um sujeito destinatário em questão. Este pode ser a voz da instituição explicitada como pergunta, ou então, numa configuração exotópica, o eco da voz do professor ou da sociedade perpassado pela voz da instituição. Temos um enunciado-pergunta que é resposta de um cenário (presente em relação ao passado) encaminhando uma pergunta para respostas deste cenário (presente-futuro). O passado é o histórico de uma visão pessimista, corrompida, que é a atuação escolar, e o futuro é o mundo glorioso, frutífero, pós-ajuda.

A utilização da forma "é" atribui predicativamente a ligação entre ensino de Matemática e fraco, ou seja, uma atribuição categoricamente disfórica das práticas do cotidiano, em que podemos atribuir "é" a tem sido, tem havido frequência.

Podemos relacionar também, para contribuir com esta interpretação, o próprio título da revista: Nova Escola. Como já debatemos anteriormente, além, então, de uma remissão ao modelo escolanovista, a presença do termo "Nova" nos sugere, neste sentido, um rompimento 
com o antigo, com a tradição, num rumo de "novas atitudes" na escola. Se temosque a proposta inaugural da revista em 1986 - e com um projeto em elaboração na década anterior a esta data - se baseou na oposição a uma "velha/antiga escola" pautada em olhares de políticas e, por conseguinte, políticas educacionais anteriores, haja vista o período ditatorial, esta oposição velho x novo, tradicional x ruptura avançou nos anos subsequentes no sentido de entender-se essa novidade como uma modernidade para o sucesso, um progressismo pessoal, isto é, a escola como meio de ascensão social.

Em (b) configura-se um cenário em que, de igual modo, podemos inferir que o discurso de Nova Escola instaura a oposição boas práticas docentes x más práticas docentes. Esta dicotomia construída pela revista reverbera uma voz dela, instituição, perante o trabalho da prática docente.

Podemos verificar que nesta trama discursiva instaurada pelos cenários apresentados pela Nova Escola estão sendo materializados valores direcionados ao fracasso escolarmatemático, colocando a revista, dessa forma, como a prestadora de um serviço que trará $a$ luz (metáfora abordada pela Fig. 2) a seus interlocutores/destinatários.

Como produto mercadológico que também é, podemos interpretar que esses discursos realizados pelo periódico se situam numa espécie de sensacionalismo midiático, configurando um confronto polarizado entre uma política neoliberalista e uma ação de contribuição social intervencionista, é dizer, há uma instigação consumista-apelativa para os destinatários da revista, haja vista que os enunciados provenientes da voz institucional instauram um cenário do fracasso nas relações de ensino-aprendizagem a fim de contribuírem com uma estratégia sócio-educacional de apoio, de intervenção e de reparação do dano fixado por meio de seu material a ser vendido.

Ao afirmar e refirmar estes cenários na prática educacional de Matemática podemos entender que a revista coloca numa trama discursiva complexa uma memória de dizer que, pela contínua presença, reflete um discurso estereotipado relacionado ao saber matemático: o da dificuldade de aprendizagem em matemática, o de que esta disciplina/este saber científico é para poucos, para os iluminados.

A imagem do iluminado é recorrente na história ocidental e oriental. Toda esta ideia cultural de expansionismo clareador nas trevas relega à luz o sentido potente de vigor, de inovação, de mudança. Porém, ao investigarmos a aplicação desta luz aos sujeitos, temos um elitismo selecionador de poucos. Na história das ciências, a memória discursiva de nossa cultura perante a iluminação passou pelo elitismo que o saber científico (e especifiquemos, o saber clássico da racionalização via matematização) foi atravessando, além de todo um envolvimento a questões ligadas ao sobrenatural/religioso em que o iluminado era dotado por um dom, uma facilitação não humana (sobre-humana) para uma ordenação do mundo. Desse modo, Nova Escola atualiza esta memória sobre o iluminado, mas que por uma iluminação - a pedagogização teórica - este cenário não poderia ser garantido.

Ao enunciar em sua capa "Uma nova luz sobre a TABUADA" (figura 2) com um cenário mais escuro, iluminado pela lanterna e pelas letras, podemos investir de sentidos que a interpretação do fracasso se realiza na não iluminação dos sujeitos perante o assunto da tabuada, estando estes sob luzes outras, orientando-nos que elas (já) são velhas, ultrapassadas, não suficientes, não esclarecedoras, ou seja, estas luzes são as práticas fadadas ao cenário do fracasso.

Elenquemos três modos da representação da memória deste fracasso:

1) Na figura dos estudantes: o erro se situa no aluno, aquele sem luz, que não faz presente a base do raciocínio, que seria representado simbolicamente por uma urna/um vaso no qual são colocados os fluidos do saber; 
2) Na figura do professor: que fracassa perante o ensino e precisa de ajuda por não saber se comunicar bem. É o professor a figura que constitui a relação fundamental entre as diversas instâncias do poder público (políticas) e a rede de ensino (educação) e não a escola como instituição em si;

3) Nas relações escolares: em que raciocínio e expressividade não são trabalhados para um saber atuante. Sendo o fracasso da aprendizagem matemática recorrente nos discursos de Nova Escola sobre aula de matemática, o trabalho conjunto da escola e os instrumentos de avaliação não são reconhecidos, assim, como meios para instrumentar as ações educativas, mas sim motivos para a produção de manchetes sensacionalistas revestidas de uma política doutrinadora.

Numa atitude responsiva, num movimento de contrapalavra, podemos interpretar que associada ao discurso de Nova Escola, associada à salvação, está a culpa. A revista tem trabalhado, em seus números abordados, o viés da incompetência num legado de culpabilização de um cenário por meio destes modos de representação da memória. Estes são espaços/pilares da exclusão dos sujeitos tomados por um discurso elitista do poder, pois temos a postos artifícios de auxílio perante cenários do não saber fazer.

Num discurso da vida idealista, que não toma o acontecimento como base de atuação e em nome de uma manutenção da ordem neoliberal vinculada à globalização e hegemonia de um pensamento único, o discurso instrucional de Nova Escola à escola coloca nestas duas instituições, a revista e a escola, vozes apregoadoras de salvação, uma voltada para o professor e outra para os estudantes e a sociedade. Associada à salvação há a culpa. Como colocamos anteriormente, a dinâmica mercadológica, no nosso caso em Nova Escola, tem culpabilizadoa instituição escola pelo fracasso escolar a fim de lucrar em cima desta questão com a venda de "receitas" de salvação. Nesta direção, podemos atrelar a discussão paralela, agora na esfera educacional, de que as políticas educacionais fincadas num neoliberalismo econômico tomam como padrão parâmetros de conteúdos a serem ensinados e avaliados posteriormente em testes locais e internacionais constituem uma espécie de "educação bancária" - como Paulo Freire (1975) já havia exposto - que produz resultados de hierarquização de instituições de ensino, apontando quais redes (cor)respondem ao 'mercado consumidor'. Como pensar em formação pessoal que valorize os espaços subjetivos e intersubjetivos pela reflexão, como pensar em caráter propedêutico ao Ensino Superior perante esta logística capitalista, idealista e estabilizadora dos momentos aula da Escola Básica?

Este estereótipo de insucesso escolar toma por base questões sociais que um amplo quadro de instituições educacionais brasileiras vem mostrando: o isolamento dos estudantes principalmente dos anos iniciais - no sentido de afastá-los da marginalidade que as ruas oferecem, já que estas representam os problemas da sociedade. Pergunta-se: por que dicotomizar vida na escola e vida fora da escola? Teria o espaço da escola a incumbência de cuidar da violência ligada às famílias, cuidar dos casos de saúde pública, cuidar da alimentação de cada um e tantas outras questões para a sobrevivência? E o cuidado com a reflexão, com o pensamento? Estes também entram nos objetivos das escolas? Cabe-nos, enfim, tomar um diálogo-dialético com as questões políticas corroborando com a ideia de que o embate de posicionamentos políticos de cada sujeito é a luta contra o esvaziamento crítico, funcional e formacional da instituição escola.

Continuemos a formar um cenário interpretativo. Tomemos, agora, a edição de número 89, de novembro de 1995, e 113, de junho/julho de 1998. 


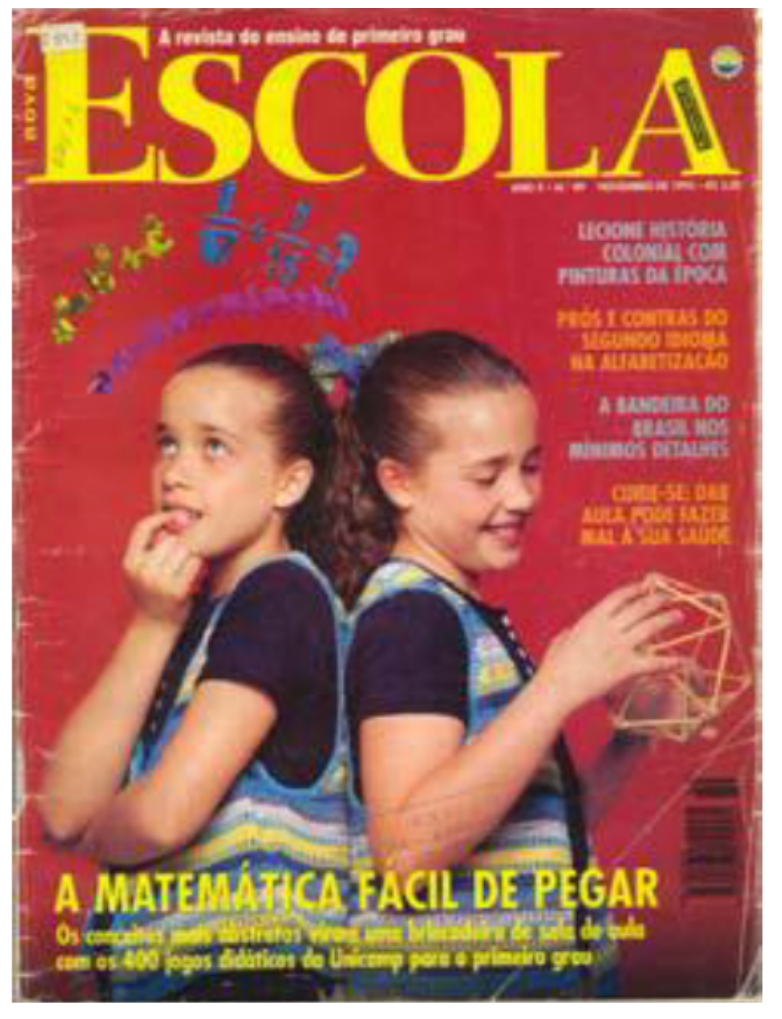

Fig. 3 - Nova Escola no 89.

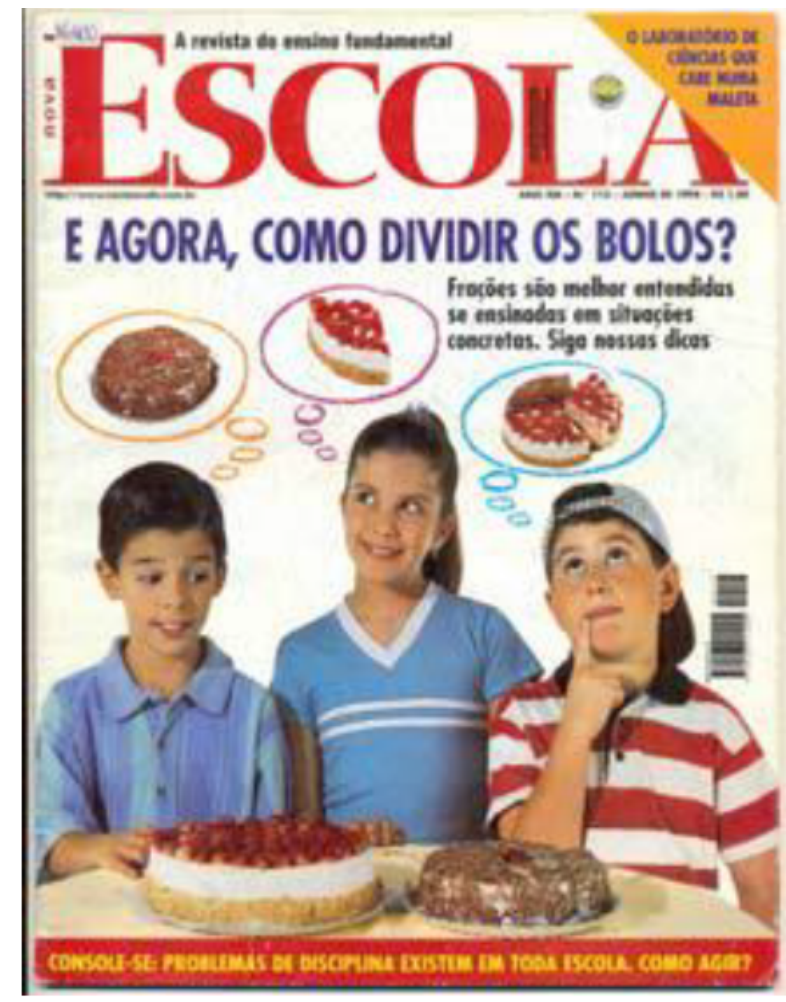

Fig. 4 - Nova Escola $\mathrm{n}^{\mathrm{o}} 113$.

Enquanto a edição 89 instaura uma voz sobre a dificuldade de aprendizagem em matemática, a edição 113 já propõe um desafio. Na inter-relação entre $\mathrm{AD}$ e Educação, estamos entendemos que, mediante questões sobre o desenvolvimento de raciocínio, propor uma dúvida é instaurar uma barreira a ser solucionada visando, neste "entrave", ao amadurecimento psicobiológico. A marca da alteridade está expressa nesta última chamada de capa e a temos materializada por meio da representação do pensamento nos balões em cima da cabeça das crianças. Podemos analisar que cada criança prevê modos diferentes de recorte, de distintos modos de partilha fracionária como resolução de um problema instaurado.

Discutindo mais sobre a capa da edição de $\mathrm{n}^{\mathrm{o}} 113$, podemos dizer que a diversidade de caminhos refletida pelas crianças/pelos estudantes marca uma noção sobre a variabilidade na possibilidade de resoluções perante a situação expressa. Contrariamente a uma visão de exatidão sobre a disciplina Matemática, aqui há o espaço da reflexão - dialética por si -, espaço em que o lúdico reforça caminhos do possível, do devir. São nestes rearranjos que podemos perceber que a instauração da alteridade pela barreira que é o outro constrói um cenário típico de aula de matemática: o cenário povoado de vozes que exigem do sujeito um posicionamento diante de desafios por problemas matemáticos.

É interessante ressaltar alguns aspectos: à pergunta em discurso verbal "E agora, como dividir os bolos?" é-nos apresentada uma ilustração em que o material com que se lida não são blocos como tijolos ou materiais de plástico, mas sim comidas: bolos e tortas. Podemos dizer que enquanto o discurso verbal reporta a uma pergunta feita pelo professor (de matemática) - seu destinatário no 'consumo' direto da revista -, a imagem do pensamento das crianças/dos estudantes é baseada numa propriedade organoléptica e multissensorial, no gosto, na alimentação, sentido que podemos estender metaforicamente a uma ideia de alimentar-se pelo conhecimento matemático. Pela relação discursiva instaurada no enunciado entre 'estudar matemática' e 'alimentar-se' nos emerge uma reflexão do paralelismo entre essas atitudes resultando, deste imbricamento, a configuração de que a matemática, assim 
como se alimentar, é essencial à manutenção da vida e de que nas situações de alimentação, assim como nos estudos matemáticos, são necessárias reflexões relacionadas à seleção, organização e distribuição. Neste último quesito, a ideia da partilha pode nos trazer a sugestão da (sobre)vivência humana ligada ao compartilhamento, no caso tanto de comida quanto de cultura matemática.

A pergunta "E agora, como dividir os bolos?" é feita por quem? Que sentidos podemos desdobrar além de estar esta pergunta na autoria dos estudantes? Pois bem, se Nova Escola se orienta aos profissionais em Educação, podemos interpretar que há uma certa representação metafórica em que a voz e a memória do dizer dos sujeitos alunos vêm à cena para que o assunto sobre frações seja discutido pelas relações de ensino.

O discurso salvacionista da revista perante o cenário decadente das relações de ensinoaprendizagem está marcado na subchamada da edição: "Siga nossas dicas". Em "Frações são melhor aprendidas se ensinadas em situações concretas", qual seria a situação inversa do ensinar de frações em situações concretas? Podemos inferir uma oposição concretox abstrato. Há, aqui, uma dualidade instaurada pelo discurso de Nova Escola para a "realidade" aula: ensino prático $\mathrm{x}$ ensino teórico.

Essa dualidade pode ser encontrada na capa da edição de $n^{0} 89$, em que duas crianças, podendo ser as mesmas ou até então gêmeas, encontram-se ombro a ombro, numa relação de parâmetro espelhar. Desenvolvamos: podemos associar a imagem do espelho para tratar inicialmente da central dicotomia que interpretamos nesta capa. As meninas se encostando dorsalmente mostram-nos processos diferentes de práticas de ensino/aprendizagem. A imagem delas não configura um enantiomorfismo, nem mesmo um eixo simétrico com a propriedade física da reflexão de imagens. Podemos interpretar que há uma semelhança imagética, materializada pelas cores das roupas congruentes, pela percepção de que são as mesmas garotas, mas em planos distintos ou que são gêmeas, guardando a ideia do princípio da identidade da forma. Ao invés de uma reflexão espelhar total, temos uma refração espelhar, onde a imagem refletida seja deslocada, não seguindo as mesmas linhas de imagens, isto tanto da direita para a esquerda (sentido comum da escrita em língua portuguesa) quanto da esquerda para a direita.

Partindo deste debate sobre Física, podemos associar a estas discussões a posição teórica do círculo bakhtiniano sobre reflexão e refração dos signos. Partindo de tal, estamos entendendo que há uma oposição ideológico-discursiva instaurada na capa desta edição que ilustramos.

Podemos interpretar que a oposição concretox abstrato relacionada às práticas escolares das aulas de matemática materializa-se mais uma vez nas capas de Nova Escola. De um lado (esquerdo) temos os olhos voltados da garotinha de sentido para cima, ressaltando o abstrato como o espaço do trabalho do pensamento. Do outro lado (direito) temos os olhos voltados para baixo, ao mesmo tempo que as mãos ganham um caráter operatório e os conteúdos matemáticos se materializam.Fazendo uma análise amparada pelas discussões desenvolvidas nos últimos tempos no Brasil na perspectiva da Educação matemática de contribuições via História, da Filosofia e da Sociologia ${ }^{100}$ podemos discutir esta capa atribuindo a oposição metodológica entre método intuitivo x método dedutivo, reforçando a dicotomia concretox abstrato, mas agora dentro de uma instância categórico-metodológica.

A perspectiva filosófica do método intuitivo nas práticas escolares na Matemática diz respeito, por exemplo, a desenvolvimentos de atitudes que trabalham a atenção aos objetos que o professor leva para a aula. Assim, uma aula de Geometria em que o professor desenvolva ações com objetos, realizando um manuseio de distintas formas, toma por base o

100 Citemos: D’Ambrosio (1996, 1999); Miguel e Miorim (2004); Miguel (2005); Miguel e Brito (1996); Nobre (1996); Baroni e Nobre (1999); Fauvel (1997). 
ensino via experimentalismo intuitivo. As práticas de perspectiva no método dedutivo dizem respeito a um caráter racionalista, visando a uma força argumentativa do pensamento. Esta tem a ver com uma lógica de sistemas, de um recorte de mundo. Em aulas de Matemática, por exemplo, temos o espaço da transposição da língua materna para a escrita matemática, fazendo com que os estudantes se apropriem formalmente de uma expressividade cultural construída ao longo do tempo pelas sociedades humanas.

Temos, desta forma, princípios que corroboram, de um lado, um trabalho com sequências de atividades indutivas que garantam uma cristalização de um foco almejado pela abordagem do professor e, de outro lado, no caso da tradição dedutiva, uma sequencialização baseada na constante memorização das formas cultural-formais. Estes dois lugares metódicos vão polarizar, assim, a noção de instabilidade x estabilidade, respectivamente.

Tomemos, agora, a imagem das meninas/gêmeas correlacionando-a à chamada da capa: "A MATEMÁTICA FÁCIL DE PEGAR". A leitura da oposição entre concreto x abstrato e indução $\mathrm{x}$ dedução é também representada, além da imagem na qual viemos discutindo, no enunciado verbal da chamada de capa. A noção verbal de "pegar" tem fundamentação com 'adquirir', 'tornar para si', 'apropriar-se'. "PEGAR" também aborda o trabalho do sujeito para a posse de algo, no sentido de 'entender' o como fazer. Podemos entender, assim, que há uma instância de dicotomização, mas há um espaço de privilégio à noção da realidade concreta, estável. Há, assim, uma configuração de encaminhamento do tácito para o explícito legitimando a forma do visível, pois é nela que a escola realmente se preocuparia: os resultados. Podemos argumentar que é este um cenário que Nova Escola instaura visto que quem "pegará" a matemática são os professores, isto é, quem tomará informações explícitas dos estudantes (e isto se chamará aprendizagem!) serão os professores. Desta forma, num modo de tecnicismo pedagógico, o aluno oferecerá ao professor uma resposta diretamente ligada à forma que ele o ensinara. A obtenção deste retorno é um termômetro do professor referente à metodologia empregada voltando-se, assim, único e exclusivo sucesso e única e exclusiva culpa dos acontecimentos.

Para fechar provisoriamente esta questão sobre concreto x abstrato, uma outra análise que corrobora nossas reflexões diz respeito à forma geométrica manuseada por uma das meninas. Num processo de leitura da capa na influência da leitura no sistema de escrita do português, da esquerda para direita, nesta transição, chamemos a atenção que é a menina à direita que toma para si o domínio do concreto. Filosoficamente temos à esquerda o idealismo platônico, do mundo das ideias e à direita o domínio do sensível, do mundo dos sentidos.

O caminho orientado pela revista segue do espaço dificultoso do raciocínio/ da elaboração para o espaço da apreensão/aprendizagem dita concreta, realizada, uma vez que, como temosnesta capa, esta condição garantiria a felicidade da conquista, condição esta materializada pela imagem da menina à direita. Para nós, Nova Escola está enunciando um valor discursivo que quer chamar uma atenção para o lado concreto da dicotomia instaurada por ela, visto que, pela nossa interpretação, a instituição se coloca a serviço da solução dos conflitos causados pela dificuldade de aprendizagem em Matemática causada pelo domínio racionalista de abordagem de ensino, cabendo às práticas concretas serem táticas que permitirão o acesso ao domínio matemático. Ainda dicotomizando, há aqui uma outra oposição: a de teoria x prática.

\section{Conclusão}

A importância de nosso debate para a legitimação de trabalhos com escopo interdisciplinar está embasada num caminho de reflexões gerado no interior da crítica educacional-pedagógica da área sobre estudos matemáticos e de reflexões em leituras em Educação e aspectos discursivos. 
A propriedade ser professor traz uma dinâmica da "(re)transmissão" de formas, conteúdos e ideologias, porém fazendo dessa ação-resposta um ato novo pela complexidade do acontecimento discursivo: sujeitos distintos com novos projetos de dizer, vivências distintas, maneiras de apropriação distintas (subjetivações).

Como questionamos, o processo da transposição didática pelo qual o direcionamento científico-pedagógico passa e no qual os docentes da Escola Básica se alocam, tem tido como pauta principalmente em saberes produzidos não apenas pelos cursos das academias universitária de formação inicial, mas também pelas maneiras organizacionais e executivas de projetos na própria instituição escolar. Os "sujeitos-alunos-professores" participam de uma trama onde o conhecimento não é produto final acabado, como telosa ser alcançado e adquirido, mas sim é instável, em estado de incompletude e na intensa provisoriedade. Há, desta maneira, a presença de um trabalho contínuo de movimentação sistemática.

Enquanto sistemas de regramento de sentidos, o gênero discursivo capa vai sendo constituído no interior das relações de comunicação. Os múltiplos sentidos dos enunciados que o compõem vão se delineando ao longo do tempo, inscritos na histórica temporalidade do ato (res)significativo dos fios discursivos. Os enunciados verbovisuiais se orientam por estas tramas do vir a ser. As dimensões verbal e visual se intercruzam para amalgamarem vozes em circulação social.

\section{REFERÊNCIAS}

ATHAYDE JÚNIOR, Mário Cândido de. Articular vozes: deslocar sentidos: o ensino de lingua portuguesa em discursos oficiais e em falas de professores. Tese de doutorado. Campinas: Unicamp, 2006.

BAJTÍN. M. M. Problemas de la obra de Dostoievski [enruso]. Moscú: Alkonost, 1994 [1929].

BAKHTIN, M./VOLOCHINOV, V. N. Marxismo e Filosofia da Linguagem. 6. ed. São Paulo: Hucitec, 1992.

- Marxismo e filosofia da linguagem: Problemas fundamentais do método sociológico na ciência da linguagem. Trad. Michel Lahud e Yara Frateschi. Vieira. 11 ed. São Paulo: HUCITEC, 2004.

BUBNOVA, Tatiana. Voz, sentido e diálogo em Bakhtin. In: Bakhtiniana, São Paulo, 6 (1): 268-280, Ago./Dez. 2011.Versão para o português: Roberto LeiserBaronas e Fernanda Tonelli.

D'AMBROSIO, Ubiratan. História da Matemática e Educação. In: FERREIRA, Eduardo

Sebastiani (Org.). Cadernos CEDES 40. Campinas: Papirus, 1996.

. A História da Matemática: questões historiográficas e políticas e reflexos na Educação

Matemática. In: BICUDO, Maria Aparecida Viggiani (Org.) Pesquisa em Educação

Matemática: concepções e perspectivas. São Paulo: UNESP, 1999.

FAUVEL, J. A utilização da História em Educação Matemática. Tradução: Paulo Oliveira. In: VIEIRA, A; VELOSO, E. LAGARTO, M. J. Relevância da História no Ensino da

Matemática. GTHEM/APM. Grafis, 1997.

FERREIRA, Carlos Eduardo da Silva. O discurso sobre a aula de matemática: articulando vozes na revista Nova Escola. Dissertação (Mestrado em Linguística e Língua Portuguesa) Unesp, Araraquara-SP. 2015.

FIORIN, José Luiz. Introdução ao pensamento de Bakhtin. São Paulo: Ática, 2008.

FREIRE, Paulo. Pedagogia do oprimido. 3. ed. Rio de Janeiro: Paz e Terra, 1975. 
MIGUEL, Antonio. História, filosofia e sociologia da educação matemática na formação do professor: um programa de pesquisa. Educação e Pesquisa, São Paulo, v. 31, n. 1, jan./abr. 2005. p. 137-152

MIGUEL, Antonio; GARNICA, Antonio Vicente Marafioti; IGLIORI, Sonia Barbosa Camargo; AMBROSIO, Ubiratan D'. A educação matemática: uma área de conhecimento em consolidação. O papel da constituição de um grupo de trabalho dessa área na ANPED. Disponível em:

$<$ http://www.ufrrj.br/emanped/paginas/conteudo_producoes/docs_26/educacao.pdf $>$. Acesso em 05/09/2012.

MIGUEL, Antonio; BRITO, Arlete de Jesus. A história da matemática na formação do professor de matemática. In: FERREIRA, Eduardo Sebastiani (Org.) Cadernos CEDES 40. Campinas: Papirus, 1996. Consulta:

$<$ http://professoresdematematica.files.wordpress.com/2010/03/a_historia_da_matematica_na

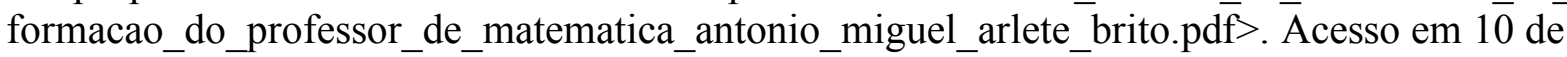
fevereiro de 2014. 1998 . et al. História da matemática em atividades didáticas. 2 ed. rev. São Paulo: Atual,

MIORIM, M. A. Introdução à História da Educação Matemática. São Paulo: Atual, 1998. MIORIM, Maria Ângela; MIGUEL, Antonio. A prática social de investigação em história da matemática: algumas considerações teórico-metodológicas. In: Anais do VI Encontro Brasileiro de Estudantes de Pós-graduação em Educação Matemática (VI EBRAPEM), Vol I, 2002, p. 7-17. ISBN: 85-86091-53-7. Campinas, SP: Gráfica da Faculdade de Educação da UNICAMP, 2002.

NOVA ESCOLA. São Paulo: Fundação Victor Civita, 1986-2012.

SILVEIRA, F. R. Um estudo das capas da revista Nova Escola: 1986-2004. Campinas, 2006. Dissertação (Mestrado em Educação) - Faculdade de Educação. Universidade Estadual de Campinas.

Recebido em 07/08/2017

Aceito em 23/11/2017 